International Journal of Advanced Trends in Computer Science and Engineering Available Online at http://www.warse.org/IJATCSE/static/pdf/file/ijatcse1351032021.pdf https://doi.org/10.30534/ijatcse/2021/1361032021

\title{
Impact of COVID-19 on publics Internet and TV Watching behavior: A cross-national Study
}

\author{
${ }^{1}$ Hamza Rehman Butt \\ Student of BS Mass Communication and Media Studies, GIFT University Gujranwala, Punjab, Pakistan \\ ${ }^{2}$ Dr Shahid Minhas \\ Assistant Professor, Department of Mass Communication and Media Studies, GIFT University Gujranwala, Punjab, \\ Pakistan, shahid.minhas@ gift.edu.pk \\ ${ }^{3}$ Aysha Anwar \\ M.Phil Scholar, Department of Management Sciences, GIFT University Gujranwala, Punjab, Pakistan \\ ${ }^{4}$ Kiran Sajid \\ M.Phil Scholar, Department of Mass Communication, Lahore Leads University, Pakistan
}

\begin{abstract}
The study attempts to understand the impact of the pandemic on youth behaviors especially internet and Television watching behavior of Gujranwala City of Pakistan, Hyderabad City of India, and Beirut city of Lebanon. Covid-19 pandemic immensely impacted lifestyle as people had to stay indoors, education institutions were closed and people were encouraged to work from home. This disrupted daily routines. The main purpose of this study is to see how COVID-19 affects the public's internet and TV watching behavior in the Middle East and South Asia while they are confined. The study is qualitative in nature, survey method was used to collect the data from a sample of 469 participants of these three big cities of the selected countries. A structured questionnaire was developed and distributed via a google form. The results of the study showed that internet use and TV watching behavior changed during pandemics and confinement. The results pointed out that people of these cities engage more with the internet and Television and an increase is observed in the usage of internet and TV watching time during Covid-19.
\end{abstract}

Key words: Covid-19, Social Media, Internet Usage, TV Watching, Lifestyle

\section{INTRODUCTION}

The Covid-19 pandemic shocks the world and left many countries grappling with its impact. The pandemic affected people's livelihoods, interactions, and way of life. The effects of the pandemic on lifestyle and behavior are including disruption of social life and social anxiety.

\subsection{DISRUPTION OF SOCIAL LIFE}

With the pandemic at its peak governments put in place mitigation measures which included partial or complete lockdowns and restrictions on social and public gatherings. This meant that people couldn't meet and interact as usual, whether it's religious gatherings, parties, or political gatherings. Social behavior such as shaking hands or hugging was also prohibited. This immensely impacted lifestyle as people had to stay indoors. Schools were closed and people were encouraged to work from home. This disrupted daily routines. Venturing outside became a risk, not an adventure.

The pandemic also leads the huge economic crises. Some people were laid off while others lost their jobs completely. With reduced or no income at all people had to adapt to live below their normal budgets. This involves cutting budgets and people let go of activities or behaviors deemed to be luxuries instead of necessities.

\subsection{SOCIAL ANXIETY}

The pandemic caused anxiety across the world. Everyday news of new infections and deaths flooded the media outlets. People were worried, while others became depressed due to income losses. Social anxiety was also profound with persons with sick relatives. Quarantine cause disruption of Social norms and cultural practices. The pandemic posed a challenge in conducting activities that are considered social norms. Normally people are allowed to visit their sick relatives and some even stay with them in 
hospital. The pandemic brought an end to this. Some hospitals prohibited visits while others restricted the number of visitors. Families left their sick in hospital only hoping they'll recover and not die with no one by their sides. In some, the dead were buried in the absence of loved ones and even in mass graves.

\subsubsection{Gujranwala}

Gujranwala is the city of Punjab, Pakistan. Gujranwala is the fifth most populous metropolitan area. Gujranwala is well known as the "city of wrestles" and also famous for its food here. According to the statics, the urban population in Gujranwala in 2018 is $2,109,839$. Now, in 2021 the urban population has increased up to $2,290,461$. Gujranwala is an agricultural city, famous for its crops all over the world.Many people do day work to live their life. Thelifestyle of Gujranwala people before Covid-19 If we looked back in 2018, the people of Gujranwala had lived plain sailing life. In Gujranwala, every field was available agriculture, industries, clinical settings, business, marketing, private jobs, and private business. People worked in respective field to earn money. Economically people of Gujranwala were substantial. They had expanded their businesses in a very effective way. The people of Gujranwala were amiable, genial, kindhearted, and propitious and, acclaim others surprisingly. They always felt honorable when any guest arrived at their home. They always welcomed guests open-heartedly. They live in wide and open houses, loved nature. You can see beautiful plants in the dwelling place of the Gujranwala. The people of Gujranwala were very fond of food. The food streets were full of people till late at night. The people of Gujranwala had celebrated their religious festival. Everyone was allowed to participate in a religious celebration. People of Gujranwala loved to visit places. They were also very fond of outings. The lifestyle of Gujranwala people afterCovid19(2019-2021)

COVID 19 pandemic has a terrible impact on Gujranwala. Pandemic has developed trade barriers for traders. People are restricted to go out and execute work activities. They cannot go out and perform their regular activities. The poor people ran out of money. Bread cutters are badly affected by the pandemic, due to this, no one is hiring them to work. The scarcity of opportunities has been everywhere. People have gone to isolation. Many psychological issues have been rising during the pandemic. People are suffering from mental illnesses, depression, and anxiety. People are horrified and terrified by the terrific situation. People are becoming anxious, present, they are less social. People have been keeping distance from affected family. The economic status has been fallen inadequately during the pandemic. Still, people are restricted to do social activities. The pandemic has affected wholesome the life of the Gujranwala people. Closure of their business caused scarcity of money for people of every class.

\subsubsection{Beirut}

Beirut is the capital and largest city of Lebanon. According to the 2014 census, Beirut has a 2.2 million population, which makes Lebanon is the third-largest city in Levant Region. Beirut was also established almost 5,000 years and was once one of Phenicia's most famous city ranking it one of the world's oldest cities.

\section{The lifestyle of Beirut people before Covid-19}

In Lebanon, there is no caste system. The most essential component in determining class boundaries is now money. In the cities, all Christians and most Muslims wear in European style. Lebanon has a fairly good healthcare system, as well as a few free hospitals. In Lebanon, there are a large number of volunteers, many of which, like Friends of the Disabled, welcome members of all faith. Several nonprofit groups assist the needy. Arranged weddings are uncommon, but they do happen. Due to the country's current economic crisis, money, a stable job, and a comfortable home have become important factors in arrange marriages.

Rice is almost a basic in the kitchen, and pasta is highly popular. Many dishes include salted yogurt. Red meat and chicken are widely available, although they are usually consumed as part of a meal. Large meals are served around sundown during Ramadan, the Muslim month of fasting. During Ramadan, soup, chickpea, and yogurt dishes (fatteh), and nut-rich pastry (karbooj) are popular dishes. Christians eat vegetarian food during Lent and a variety of wheatbased foods at Halloween (Barbara).

The lifestyle of Beirut people after Covid-19 (2019-2021)

During Covid-19 in Beirut, the major problem is economic issues. Covid-19 disturbs the economy of the whole world. Lebanon also has an economic issue before Covid-19 and the pandemic increases their 
Hamza Rehman Butt et al., International Journal of Advanced Trends in Computer Science and Engineering, 10(3), May - June 2021, 2459 - 2468

economic issues. That way the people of Beirut's lifestyle are disturbed. Otherwise, life in Beirut's people has no significant change. But due to economic issues life is badly disturbed. Because Lebanon government imposed full lockdown many times that why people lifestyle is disturbed.

\subsubsection{Hyderabad}

Hyderabad is the capital and largest city of Telangana. According to the 2011 census, Hyderabad has a 6.9 million population, which makes Hyderabad is the sixth most populated city in India. Hyderabad became the capital of the newly constituted Andhra Pradesh after the States Reorganization Act of 1956 was passed. Andhra Pradesh was divided into Telangana in 2014, and Hyderabad was declared as the combined capital of the two states, with a temporary arrangement set to expire in 2024.

The lifestyle of Hyderabad people before Covid-19 Hyderabad is a state with a lot of history and landmarks. Many tourists come to Hyderabad from all over the world to participate in the local customs and ceremonies. Hyderabad hosts a diverse range of festivals. The Deccan Festival, one of the most popular festivals, is held in February or March by the Department of Tourism. Hyderabad's language, clothing, and food all play an important role in shaping Indian culture.Hyderabad's history is wellknown for its world-famous Hyderabadi Biryani. Hyderabadi Biryani has been a Mughal tradition since the Mughal era.Hyderabadi cuisine is known around the world for its wonderful flavors, which are achieved by the use of spices and the extensive use of meats, ghee, herbs, natural delicacies, and dry fruits. When we think of Hyderabadi food, the Traditional Hyderabadi Dum Biryani comes to mind first, which is served in restaurants all over the country.All religions, including Hinduism, Islam, Christianity, Buddhism, and Jainism, coexist and share mutual interests. Inside the city, there were many famous temples, mosques, and churches. Women wear Indian sarees and Salwar Kameez, while men wear Kurta Pajama and Sherwanis. From bangles to sandals, Hyderabadi ladies have a great sense of matching.

The lifestyle of Hyderabad people after Covid-19 (2019-2021)

This pandemic not just unfavorably influenced the actual soundness of people, yet in addition delivered critical changes in their way of life. India has a broadly perceived medical services conveyance framework yet because of the absence of a coordinated foundation, there is a developing feeling of emergency, as the greater part (66.53\%) of its populace live in rustic regions which are tormented with wide inconsistencies identified with the conveyance of medical service's needs. This pandemic has amplified this deficiency by redirecting its attention on explicit ailments, disregarding different issues identified with way of life conduct.Because this emergency (COVID-19) resembled the developing number of cases, there was a quick spike in the requirement for a few preventive and defensive apparatuses in particular N-95 veils, individual defensive hardware (PPE units), ventilators, thermo-controllers, and so on, and because of which, most of the current medical care offices/focuses were either transformed into devoted COVID-19 focuses or existing wellbeing assets were moved to COVID-19 administration. Wellbeing and prosperity are the needs of any country, accordingly, India went through maybe the strictest lockdown in 5 stages following incomplete open down alongside proposals like limitations on opportunity of development, social and physical removing, selfdisconnection, and isolate measures, and so forth, to control down the illness spread. While the whole country is step by step advancing through the cycle of continuous 'opening', alongside the overall condition of imprisonment one next to the other, there is a need of great importance to survey the effect of COVID19 on changes in way of life conduct among people. Ostensibly all these predominant limitations may have had bearing on the eating or dietary propensities, rest status, actual work, and mental pressure, finishing in deteriorating both the physical and psychological well-being among the majority.

\subsection{RESEARCH OBJECTIVE}

- To under the impact of Covid-19 pandemic on publics internet and TV watching the behavior of Gujranwala, Hyderabad, and Beirut.

- To investigate how COVID-19 hasan impact on the lifestyle behavior of the people of Gujranwala, Beirut Hyderabad.

- To determine what significant changes come after COVID-19 in the internet, TVwatching behavior.

- To examine people's perspective regarding the change in lifestyle behavior due to COVID-19 in Gujranwala, Beirut Hyderabad. 
Hamza Rehman Butt et al., International Journal of Advanced Trends in Computer Science and Engineering, 10(3), May - June 2021, 2459 - 2468

- To comparatively analyze lifestyle behavior of Gujranwala, Beirut Hyderabad.

- To what extent COVID-19 changes the lifestyle behavior of the people of Gujranwala, Beirut Hyderabad.

\section{LITERATURE REVIEW}

According to research studies, during the first two months of the COVID-19 pandemic; we saw numerous notable changes among Brazilian urologists, which we documented in our paper. Patients' visits, elective and emergency procedures have all decreased significantly for urologists. Since the emergence of COVID-19, a small number of Brazilian urologists have begun performing nonessential operations. Most, especially those in private clinics have seen a significant reduction in their income, forcing cost-cutting processes in both their professional and personal lives. Including such main professional changes, considerable changes in the physical condition and daily life have been reported, including weight gain, decreased physical activity, increased alcoholic beverage use, and decreased sexual engagement. Finally, 13.5 percent of the urologists who took part in the study were diseased with SARS-CoV-2, and almost a third of them needed to be hospitalized. COVID-19 had claimed the lives of fourBrazilian urologists as we prepared this article, to which we dedicate this research. [1]

This study is the first to survey thousands of people across the globe onlifestyle behavior changes in response to stay-at-home orders. Although the current survey does not capture diet composition per se, individuals reported a combination of positive and negative changes in eating behaviors. Declines in healthful eating behaviors were coincident with reductions in physical activity, and these negative behaviors were characteristic of individuals reporting weight gain in response to the pandemic outbreak.Increased overall healthy eating scores were primarily due to the reduction in eating foods prepared outside the home, an almost unavoidable change to food intake that resulted from stay-at-home orders. This finding is confirmed by a report from Hunter Food and BeverageCommunications, which surveyed 1,005 individuals living in the US and showed that $54 \%$ of individuals reported cooking more frequently since the start of the pandemic. Other positive dietary changes included a reduction in fried foods, which are generally a product of restaurant dining and fast food.The reported decline in physical activity is supported by objective data fromFitbit, Inc, whose monitor data detected a 7\%$38 \%$ decline globally since the start of the pandemic. Our study provides additional evidence that declines in physical activity are characterized by a shift toward lower-intensity activities. The magnitude of change observed through our survey is comparable to declines detected by Fitbit, Inc.Total minutes spent in physical activity declined by $6 \%$ and intensityadjusted minutes declined by $8 \%$, whereas time spent jogging and running, which is more easily detected by watch-worn activity monitors, declined by $13 \%$ and $10 \%$, respectively. Leisure sedentary behaviors increased more on weekdays compared with weekend days. These disproportionate increases could be attributed to changes in structured workdays, time gained from ceasing a workplace commute, or a replacement of other forms of entertainment that would typically occur outside the home. Declines in physical activity were less for participants residing in the US compared with outside of the US (Supporting Information Table S1). However, these changes are likely attributable to overall lower levels of physical activity of participants residing in the US before the pandemic. This study is the first to survey thousands of people across the globe on lifestyle behavior changes in response to stay-at-home orders. Although the current survey does not capture diet composition per se, individuals reported a combination of positive and negative changes in eating behaviors. Declines in healthful eating behaviors were coincidentwith reductions in physical activity, and these negative behaviors were characteristic of individuals reporting weight gain in response to the pandemic outbreak.Increased overall healthy eating scores were primarily due to the reduction in eating foods prepared outside the home, an almost unavoidable change to food intake that resulted from stay-at-home orders. [2]

According to a study on "The impact of COVID-19 stay-at-home orders on health behaviors in adults". This is the first study to survey thousands of people throughout the world about how their lifestyles have changed as a result of stay-at-home orders. Individuals reported a mix of good and negative changes in eating patterns; although the current study does not measure diet composition per se. Declines in healthy eating habits correlated with decreases in physical activity, and these negative experiences were common among people who gained weight as a 
Hamza Rehman Butt et al., International Journal of Advanced Trends in Computer Science and Engineering, 10(3), May - June 2021, 2459 - 2468

result of the pandemic outbreak. The reduction in eating foods producedoutside the home, a nearly unexpected adjustment in food intake that occurred from stay-at-home orders, was principally responsible for improved overall healthy eating scores. This is confirmed by a report from Hunter Food and Beverage Communications, which studied 1,005 people in the United States and found that 54 percent of them had increased their cooking frequency since the pandemic began. Our research adds to the growing body of data that losses in physical activity are accompanied by a shift to lowerintensity activities. The magnitude of shift revealed by our survey is equivalent to Fitbit, Inc.'s declines. Total time spent in physical fitness decreased by $6 \%$, with frequency-time decreasing by $8 \%$, while time spent walking and sprinting, which are easier to detect with wrist-worn activity monitors, decreased by $13 \%$ and $10 \%$, respectively. Free time inactive habits increased more on days than on weekends. Changes in a daily work routine, time gain from removing a business commute, or the replacement of many other types of entertainment that would normally take place outside the home could all account for these variations. Participants who lived in the United States had fewer declines in physical activity than those who lived outside of the country. However, these changes are most likely due to participants' poor level of physical activity before the epidemic in the United States. [3]

The COVID-19 epidemic has killed millions of people, infected them, or left them healthy. During the COVID-19 epidemic, people were highly stressed about food security and immune-boosting medicines, according to our data. This shows that lockdown has a tremendous impact on the economy, food sector, and behavior. People's dietary and lifestyle choices have been altered by the restricted movement since people tend to replace outside activities with sedentary indoor pursuits. For example, Consumers are more willing to shop online, cook at home, access food delivery services, watch Netflix, and play video games. People feel relaxed, because the outdoors, plants, flowers, relaxation, cycling, and the search for meditation were all positively associated with the daily confirmed events of COVID-19. [4]

According to the study of the COVID-19 pandemic, the most common advice is to limit everyday activities, such as distant work and school, social isolation, and quarantine to one's house. However, these restrictions for quarantine and social isolation may have a negative impact on public health because home quarantine reflects changes in daily life behaviors, such as reduced physical activity and excessive consumption of unhealthy foods, which can lead to metabolic disorders like overweight, diabetes, and hypertension. Furthermore, the social isolation that comes with house confinement raises the risk of psychosocial distress. During quarantine, a prior study looked at the daily life behaviors of 1047 people from various countries. A higher proportion of people are suffering from psychosocial and emotional illnesses, which have been linked to unhealthy lifestyle habits like physical and social inactivity, poor food, and poor sleep quality. Emotional illnesses such as depression, anxiety, frustration, and boredom have been associated with increased energy consumption, owing to the consumption of high-fat and high-sugar diets. Individuals typically opt for unhealthy food during stressful situations to reduce tension induced by unpleasant feelings such as fear, perplexity, stress, and rage. A high-fat, high-sugar diet can suppress the satiety response in the brain, activating reward circuits and leading to increased food intake. Weight gain, as well as higher blood pressure, glucose, and lipids may occur as a result of increased energy intake mixed with decreased physical activity levels owing to confinement, raising the risk of cardiovascular disease. Furthermore, because cardiovascular disease is one of the leading causes of death and disability in the world, a method of preventing or easing Cardiovascular disease progression during the COVID-19 pandemic is required. [5]

People were forced to stay indoors due to lockdown and social distancing rules, which can have a harmful impact on their health and lifestyle, mostly in urban regions. Physical inactivity, lack of exercise, spending less time participating in sports and exercise due to gym and stadium closings, Sleep schedules have become more irregular, and sleeping time has increased., overeating and intake of unbalanced food due to the unavailability of specific foods can all contribute to increasing levels of body fat, Diabetes and other health issues are the consequences.[6] Various activities, such as sleep time, physical activities, TV watching times, and family social time, have been considerably influenced by COVID-19.

Table: 1 demographic result 
Before lockdown sleeping times were reported to be less than 7 hours for 49.6 percent of respondents and after lockdown sleeping increased 7-10 hours for 53.2 percent. Physical activity has also decreased significantly during COVID-19, with 48 percent of participants reporting stop physical activities during the lockdown. In addition, during the lockdown TV watching time jumped from 1 hour to 2 hours reported from the 24 percent of the participant. Also, the usage of social media time has increased. [7]

Along with the viral epidemic, most people's growth of personal immune response has improved, but many have also suffered from stress. He thought that the lockdown stopped the spread of the infection, which had an impact on people's lifestyles and behaviors. It is extremely difficult for poor people to maintain social distancing in the absence of a proper welfare state and government support. E-learning has become more understood as a result of the lockdown. [8]

\section{METHODOLOGY}

\subsection{STUDY DESIGN}

A comparative study was conducted to observing the COVID-19 effect on lifestyle behavior. We will conduct a survey for observing the COVID-19 effect on lifestyle behavior. The survey form was designed by using "Google Form".

\subsection{STUDY POPULATION}

People who agreed to participate in the study can participate, but they should be 18 years and belong from Gujranwala, Beirut, and Hyderabad. There were no restrictions on occupation and gender.

\subsection{SAMPLING}

Participants who met the criteria were invited to take part in the study. In this study between three cities from three different countries, the sample size was generated based on the specific country scenario. The study participants will be chosen using the survey method.

\subsection{DATA COLLECTION}

Using "Google Forms," an online link to a digital questionnaire was created to collect the lifestyle data before Covid-19 and after Covid-19. The survey covered 3 cities from three different countries. The questionnaire was distributed among the city mentioned above via online platforms and social media. That is easy to access through smartphones, laptops, and computers. The colleagues have been making sure to fill the questionnaire from his targeted cities. Social media was effective because according to the most a recent report on internet activity in the MENA region 70.2 percent of people were active and 51 percent used social networking sites. [9]

\section{Questionnaire design/Study tool}

The format of the questionnaire consisted on 28 questions. That was divided into three parts, first is personal data, second daily eating routine and last is about lifestyle. First part consisting of 8 questions about personal information like age, gender, social status, education level, disease history, etc. Secondpart consisting on 10 questions that about daily eating routine like changes inweight, change in diet plan, etc. The third part is consistingof 10 questions about lifestyle like routine activities.

\subsection{RESULT AND ANALYSIS}

On May 31, the survey was conducted and collected data were analyzed. The total number of respondents is 469 . We received 183 responses from Gujranwala, 157 responses from Hyderabad, and 129 responses from Beirut

\begin{tabular}{lllllllll} 
& No of Responses & City & Age & & & & Sex & \\
\hline & & & $<18$ & $18-25$ & $25-40$ & $>40$ & $\mathrm{M}$ & $\mathrm{F}$ \\
$\mathbf{1}$ & 183 & Gujranwala & 23 & 72 & 49 & 39 & $37.5 \%$ & $62.5 \%$ \\
$\mathbf{2}$ & 157 & Hyderabad & 32 & 59 & 37 & 29 & $58 \%$ & $42 \%$ \\
$\mathbf{3}$ & 129 & Beirut & 20 & 49 & 38 & 22 & $48.5 \%$ & $51.5 \%$ \\
\hline
\end{tabular}


Hamza Rehman Butt et al., International Journal of Advanced Trends in Computer Science and Engineering, 10(3), May - June 2021, 2459 - 2468

\begin{tabular}{|c|c|c|c|c|c|c|}
\hline \multirow[t]{3}{*}{$\begin{array}{l}\text { How many times do you } \\
\text { practice physical activity } \\
\text { per week before? }\end{array}$} & \multicolumn{2}{|c|}{ Gujranwala } & \multicolumn{2}{|l|}{ Hyderabad } & \multicolumn{2}{|l|}{ Beirut } \\
\hline & Before & After & Before & After & Before & After \\
\hline & Covid-19 & Covid-19 & Covid-19 & Covid-19 & Covid-19 & Covid-19 \\
\hline Less than 1 hour/day & $44.3 \%$ & $58.1 \%$ & $34.4 \%$ & $24.8 \%$ & $35.7 \%$ & $48.6 \%$ \\
\hline 1-2 hour/day & $18.1 \%$ & $20.6 \%$ & $20 \%$ & $15.2 \%$ & $23.8 \%$ & $24.7 \%$ \\
\hline 2-3 hour/day & $7.5 \%$ & $5.6 \%$ & $14.4 \%$ & $12 \%$ & $12.8 \%$ & $8.2 \%$ \\
\hline Above than 3 hour/day & $3.7 \%$ & $2.5 \%$ & $4 \%$ & $3.2 \%$ & $8.3 \%$ & $8.2 \%$ \\
\hline None & $26.2 \%$ & $13.2 \%$ & $27.2 \%$ & $44.8 \%$ & $19.4 \%$ & $10.3 \%$ \\
\hline
\end{tabular}

Table 2: Physical activities

behavior

How many hours do you spend on the internet (study/work/social media) or TV watching per

Gujranwala

Hyderabad

Beirut day?

\begin{tabular}{|c|c|c|c|c|c|c|}
\hline & $\begin{array}{l}\text { Before } \\
\text { Covid-19 }\end{array}$ & $\begin{array}{l}\text { After } \\
\text { Covid- } \\
19\end{array}$ & $\begin{array}{l}\text { Before } \\
\text { Covid- } \\
19\end{array}$ & $\begin{array}{l}\text { After } \\
\text { Covid- } \\
19\end{array}$ & $\begin{array}{l}\text { Before } \\
\text { Covid-19 }\end{array}$ & $\begin{array}{l}\text { After } \\
\text { Covid- } \\
19\end{array}$ \\
\hline Less than 1 hour/day & $7 \%$ & $3.3 \%$ & $9 \%$ & $2.4 \%$ & $7.3 \%$ & $3.6 \%$ \\
\hline 1-2 hour/day & $11.8 \%$ & $4.3 \%$ & $20 \%$ & $11.2 \%$ & $9.1 \%$ & $2.7 \%$ \\
\hline 2-3 hour/day & $13.1 \%$ & $15.6 \%$ & $30.4 \%$ & $32.8 \%$ & $38.5 \%$ & $41.2 \%$ \\
\hline Above than 3 hour/day & $68.1 \%$ & $76.8 \%$ & $42.4 \%$ & $53.6 \%$ & $45.1 \%$ & $52.5 \%$ \\
\hline
\end{tabular}

Table 3: Internet usage behavior

Table 4: Family spent time behavior

\begin{tabular}{|c|c|c|c|c|c|c|}
\hline \multirow[t]{3}{*}{ How many hours do you spend with your family? } & \multicolumn{2}{|c|}{ Gujranwala } & \multicolumn{2}{|c|}{ Hyderabad } & \multicolumn{2}{|l|}{ Beirut } \\
\hline & Before & After & Before & After & Before & After \\
\hline & $\begin{array}{l}\text { Covid- } \\
19\end{array}$ & $\begin{array}{l}\text { Covid- } \\
19\end{array}$ & $\begin{array}{l}\text { Covid- } \\
19\end{array}$ & $\begin{array}{l}\text { Covid- } \\
19\end{array}$ & $\begin{array}{l}\text { Covid- } \\
19\end{array}$ & $\begin{array}{l}\text { Covid- } \\
19\end{array}$ \\
\hline Less than 1 hour/day & $25.1 \%$ & $17.5 \%$ & $21.6 \%$ & $29.6 \%$ & $39.4 \%$ & $34 \%$ \\
\hline 1-2 hour/day & $38.1 \%$ & $43.1 \%$ & $36.8 \%$ & $40.8 \%$ & $37.6 \%$ & $39.4 \%$ \\
\hline 2-3 hour/day & $18.1 \%$ & $23.1 \%$ & $14.4 \%$ & $13.6 \%$ & $10.2 \%$ & $11.9 \%$ \\
\hline Above than 3 hour/day & $11.8 \%$ & $13.1 \%$ & $11.2 \%$ & $8.8 \%$ & $7.3 \%$ & $10.2 \%$ \\
\hline None & $6.9 \%$ & $3.2 \%$ & $16 \%$ & $7.2 \%$ & $5.5 \%$ & $4.5 \%$ \\
\hline $\begin{array}{l}\text { As mentioned in the methodology, whose participant } \\
\text { that age is below } 18 \text { that response not count in the } \\
\text { result. So, after evaluation } 394 \text { were included. After } \\
\text { the reduction of } 18 \text { below age participant response, }\end{array}$ & \multicolumn{6}{|c|}{$\begin{array}{l}\text { the valid number of participants from Gujranwala is } \\
160 \text {, from Hyderabad is } 125 \text { and from Beirut is } 109 \text {. } \\
\text { According to the table1 total response from } \\
\text { Gujranwalais } 183.62 .5 \% \text { female are participating } \\
\text { and } 37.5 \% \text { male participate from Gujranwala in the }\end{array}$} \\
\hline
\end{tabular}


survey. That shows mostly females like to participate from Gujranwala rather than males. But if we lookat other facts and figure that we collected from Hyderabad. $58 \%$ male and $42 \%$ female are participating in the survey. That shows mostly males like to participate from Hyderabad rather than females. But if we look at those facts and figure that we collected from Beirut. 51.5\% female and $48.5 \%$ male are participating from Beirut. That shows the female like to participate from Beirut rather than male.

As we mentioned in the methodology, the survey form link shares with participants online. So, the table.1 shows that most females like to use or familiar with Internet/digital platforms. Because the high number of participants are female. That shows the most men are not familiar or maybe don't link use or participant in an online survey. Overall figure from the table. $152 \%$ female isparticipating and $48 \%$ male participate. If we talk about the overall ratio then show the female are more interested in participating in the online survey rather than male.

On the other side, if we look at who the high number of citizensparticipates in the survey. Then we see the high number of responses we collected from Gujranwala rather than Hyderabad and Beirut.Table.1 shows that Gujranwala people like to participate in online surveys rather than Hyderabad and Beirut.

Different behaviors such as sleeping hours, physical activities, TV watching hours or internet usage, smoking habit, and family quality time, have been significantly impacted during COVID-19. Some people feel a positive lifestyle change and some feel a negative change in lifestyle. The pandemic situation was stressful forall living beings. Whatever it's human or animal. Because in the first Covid-19 wave, many animals and humans die cause of Covid19.

Due to Covid-19, some change in lifestyle behavior is positive or some negative. Like as if we look at table.2. Most people start physical activities in lockdown. If we lookat the figure that we collected from Gujranwala. We saw a big change; most people startthe exercise. Also, lookat the figure of Beirut, we saw a change in lifestyle behavior. People start exercise here. But if we lookat the figure that we collected from Hyderabad. We noted that the ratio of people, who do physical activities, is decreased. But after this, we ask why they leave physical activities.
They said the lockdown and stressful conditions of Covid-19 forced us to leave exercise.

People of all ages have been limited in their physical activities due to the COVID-19 pandemic. Indoor and outdoor sports and social facilities, such as gyms, swimming pools, and parks, are closed in many countries. Children use the Internet for education and social interaction and social networking for business, entertainment, and online shopping is also now part of daily family routines.[10]

According to the table. 3 the usage of internet and TV watching time has been increasing in the cause of Covid-19. Because due to covid-19, many countries wereimposedlockdowns and it was a stressful situation for all living been. So that case, the usage of the internet and TV watching time has been increased inthe world. If we looked at the table.3, we feel in all cities the usage of internet and TV watching time has been increased.

To control the spread and consequences of the COVID-19 pandemic, various governments have implemented strategies such as physical isolation and "staying at home." People all across the world are experiencing increased stress, worry, and depression as a result of the disease, the 'lockdown' situation, high levels of uncertainty about the future, and financial insecurity. To reduce tension and anxiety, as well as to improve low mood, psychoactive substances the video gaming, and watching pornography,etc. are frequently used. [11]

According to the case study,the use of illegal drugs and other rewarding behaviors such as gambling, video gaming, watching TV series, using social media, watching pornography, or surfing the internet is frequently used to release tension and anxiety and improve mood. These potentially addictive activities may help people deal with stressful challenges and avoid issues and negative thoughts.[12]

According to Table.4, we can see a big change in daily routine. In all three cities, the daily routine change. People start to spend time with family. Because in the case of a pandemic, the mostly countries-imposed lockdown and say to stay home. The organization allowsits employees to work from home. That why the spend time with family increases [13]. According toa research study "Life in the family and at work does not interchange. We can spend time 
with our families at home while still getting work done and performing well professionally".[14]

\section{CONCLUSION}

The Study concludes that the covid-19 pandemic has disturbed social life worldwide, people were restricted to the home. Social distance and quarantine were announced compulsory for the people as well as Covid-19 affected people. Using hand sanitizer and mask were made mandatory after Covid-19 announced as a pandemic [15]. The study concluded that residents of Gujranwala, Hyderabad, and Beirut sighted a lifestyle change, as people were remains at home and they utilized their time in watching television and using the internet. The study noted a major shift in social media usage in the residents of Gujranwala and the people during confinement wasspent most of the time using social media and the internet and such tendency also observed in watching Television. And this trend is also noted in Hyderabad for watching television and internet usage. Residents of Hyderabad also noted spending more time using the internet and watching television. The same tendency was seemed in Beirut for watching television and internet usage. The study concluded that the residents of these cities' internet usage and watching television behavior seemed a major change during confinement. Residents of these cities started to exercise and other healthy activities during confinement, however, internet usage and TV watching behaviors were most dominant trend which seemed change during confinement. The study also concluded that other home-based activities were started during confinement however, healthy activities were observed to decrease. The study noticed that residents of these three cities looked stressed and uncertain.

\section{REFERENCES}

[1] Gomes, Cristiano M., Luciano A. Favorito, João Victor T. Henriques, Alfredo F. Canalini, Karin MJ Anzolch, Roni de C. Fernandes, Carlos HS Bellucci et al. "Impact of COVID-19 on clinical practice, income, health and lifestyle behavior of Brazilian urologists." International braz j urol 46, no. 6 (2020): 1042-1071.

[2] The impact of coronavirus on global activity. Fitbit website. Accessed June 1,
2020. https://blog.fitbit.com/covid-19-

global-activity/

[3] Flanagan, Emily W., Robbie A. Beyl, S.

Nicole Fearnbach, Abby D. Altazan, Corby

K. Martin, and Leanne M. Redman. "The impact of COVID $\square 19$ stay $\square$ at $\square$ home orders on health behaviors in adults." Obesity 29, no. 2 (2021): 438-445.

[4] Mayasari, Noor Rohmah, Dang Khanh Ngan Ho, David J. Lundy, Anatoly V. Skalny, Alexey A. Tinkov, I. Teng, Meng-Chieh Wu et al. "Impacts of the COVID-19 pandemic on food security and diet-related lifestyle behaviors: an analytical study of Google trends-based query volumes." Nutrients 12 , no. 10 (2020): 3103.

[5] Volino-Souza, Mônica, Gustavo Vieira de Oliveira, Carlos Adam Conte-Junior, and Thiago Silveira Alvares. "Covid-19 quarantine: impact of lifestyle behaviors changes on endothelial function and possible protective effect of beetroot juice." Frontiers in nutrition 7 (2020).

[6] Hussain, Mirza Waseem, Tabasum Mirza, and Malik Mubasher Hassan. "Impact of COVID-19 Pandemic on the Human Behavior [J]." International Journal of Education and Management Engineering 10, no. 8 (2020): 35-61.

[7] Abouzid, Mohamed, Dina M. El-Sherif, Nael Kamel Eltewacy, Nesrine Ben HadjDahman, Salah A. Okasha, SheriefGhozy, and Sheikh Mohammed Shariful Islam. "Influence of COVID-19 on lifestyle behaviors in the Middle East and North Africa Region: a survey of 5896 individuals." Journal of translational medicine 19, no. 1 (2021): 1-11.

[8] Kandel, Samikshya, Mahesh Lamsal, Saroj Adhikari Yadav, Dipak Bhandari, Ganesh Adhikari, Sagar Poudel, Pawan Sharma, and Swotantra Gautam. "Lifestyle, behavior, perception and practices of Nepalese during lockdown due to COVID-19 pandemic." JNMA: Journal of the Nepal Medical Association 58, no. 229 (2020): 690.

[9] Arafat, SM Yasir, AngiAlradie Mohamed, Sujita Kumar Kar, Pawan Sharma, and Russell Kabir. "Does COVID-19 pandemic 
affect sexual behaviour? A cross-sectional, cross-national online survey." Psychiatry research (2020).

[10] Shahidi, Seyed H., Jennifer Stewart Williams, and FahimehHassani. "Physical activity during COVID $\square 19$ quarantine." Acta Paediatrica 109, no. 10 (2020): 2147-2148.

[11] Király, Orsolya, Marc N. Potenza, Dan J. Stein, Daniel L. King, David C. Hodgins, John B. Saunders, Mark D. Griffiths et al. "Preventing problematic internet use during the COVID-19 pandemic: Consensus guidance." Comprehensive Psychiatry100 (2020): 152180.

[12] Blasi, Maria Di, Alessandro Giardina, Cecilia Giordano, Gianluca Lo Coco, CrispinoTosto, Joel Billieux, and Adriano Schimmenti. "Problematic video game use as an emotional coping strategy: Evidence from a sample of MMORPG gamers." Journal of behavioral addictions 8, no. 1 (2019): 25-34.

[13] Prime, Heather, Mark Wade, and Dillon T. Browne. "Risk and resilience in family wellbeing during the COVID-19 pandemic." American Psychologist (2020).

[14] Dr. Tasaddaq Hussain, Shahid Minhas, et al.,(2021).PATTERNS OF INTERNET USE, AND INFORMATION OVERLOAD ON UNIVERSITY STUDENTS. 64(5), 71-85.

[15] Saeed, R. A., \& Shareef, S. M. (2020). Implementation of Artificial Intelligence to Predict Threats in Social Media Based on User's Behavior. International Journal of Advanced Trends in Computer Science and Engineering, 9(5), 6931-6938. https://doi.org/10.30534/ijatcse/2020/10952 020 